\title{
Estimated Cost of Emergency Sunburn Visits- Validation of ICD-9-CM Search Criteria
}

\section{Citation}

Xia, Fan Di, Cara Joyce, and Arash Mostaghimi. 2017. “Estimated Cost of Emergency Sunburn Visits-Validation of ICD-9-CM Search Criteria." JAMA Dermatology 153 (6) (June 1): 612. doi:10.1001/jamadermatol.2017.0252.

\section{Published Version}

doi:10.1001/jamadermatol.2017.0252

\section{Permanent link}

http://nrs.harvard.edu/urn-3:HUL.InstRepos:33786911

\section{Terms of Use}

This article was downloaded from Harvard University's DASH repository, and is made available under the terms and conditions applicable to Other Posted Material, as set forth at http:// nrs.harvard.edu/urn-3:HUL.InstRepos:dash.current.terms-of-use\#LAA

\section{Share Your Story}

The Harvard community has made this article openly available.

Please share how this access benefits you. Submit a story.

\section{Accessibility}


sue volume, additional findings such as this are not totally unexpected and have been supported by the work of others. ${ }^{3}$

It was not our intention to promote immunohistochemical staining of melanoma in situ. As Rodic and Glusac point out, survival for patients diagnosed with melanoma in situ essentially matches that of healthy individuals. Given the extremely small tumor burden in the cases with occult invasion, a similar survival curve could be expected. This lack of prognostic utility, on a large scale, argues against an exhaustive search for microinvasion. It is also impractical and cost-ineffective to stain all melanoma in situ cases with melan-A. Our findings simply serve as a proof of principle that, owing to the innate limitations of routine histologic examination, a diagnosis of melanoma in situ does not always exclude invasion.

Perhaps a comparable scenario would be the finding of isolated melanoma cells in sentinel lymph nodes by immunohistochemical analysis. While the clinical significance remains a subject of debate, most laboratories routinely perform immunostains on melanoma sentinel lymph nodes, and it is not uncommon to identify tumor cells that are otherwise not detected on H\&E. ${ }^{4}$

The ultimate goal of our study was to raise awareness of the extremely low (but not zero) risk of metastasizing melanoma in situ by providing plausible mechanisms for this rare phenomenon. Given the current evidence, we respectfully argue that the concern for metastasis is not totally unwarranted, and that telling the patients they are absolutely cured without educating and monitoring them for the very low risk of metastasis may in fact be doing them a disservice.

May P. Chan, MD

Douglas R. Fullen, MD

Timothy M. Johnson, MD

Author Affiliations: Department of Dermatology, University of Michigan, Ann Arbor (Chan, Fullen, Johnson); Department of Pathology, University of Michigan, Ann Arbor (Chan, Fullen); Division of Plastic Surgery, Department of Surgery, University of Michigan, Ann Arbor (Johnson); Department of Otolaryngology, University of Michigan, Ann Arbor (Johnson).

Corresponding Author: May P. Chan, MD, Department of Pathology, University of Michigan, 1301 Catherine St, Medical Science I, Ste M3261, Ann Arbor, MI 48109 (mpchan@med.umich.edu).

Published Online: April 5, 2017. doi:10.1001/jamadermatol.2017.0197

Conflict of Interest Disclosures: None reported.

1. Bax MJ, Johnson TM, Harms PW, et al. Detection of occult invasion in melanoma in situ. JAMA Dermatol. 2016;152(11):1201-1208.

2. Megahed M, Schön M, Selimovic D, Schön MP. Reliability of diagnosis of melanoma in situ. Lancet. 2002;359(9321):1921-1922.

3. Stuart LN, Rodriguez AS, Gardner JM, et al. Utility of additional tissue sections in dermatopathology: diagnostic, clinical and financial implications. J Cutan Pathol. 2014;41(2):81-87.

4. Satzger I, Völker B, Meier A, Schenck F, Kapp A, Gutzmer R. Prognostic significance of isolated HMB45 or melan A positive cells in melanoma sentinel lymph nodes. Am J Surg Pathol. 2007;31(8):1175-1180.

\section{Estimated Cost of Emergency Sunburn Visits- Validation of ICD-9-CM Search Criteria}

To the Editor We applaud the evaluation by Guy and colleagues ${ }^{1}$ of costs for sunburn-associated visits to US emergency departments. Their analysis was performed using the International Classification of Diseases, Ninth Revision, Clinical Modifica- tion (ICD-9-CM) primary and secondary billing codes for sunburn (692.71, 692.76, and 692.77) in discharge records from the National Emergency Department Sample database.

This important analysis is hampered by the lack of validation for these search criteria, leading to concerns about the veracity of identified cases. While sunburn may appear to be a simple diagnosis, other attempts to validate ICD-9-CM criteria for dermatologic diagnoses have demonstrated poor predictive value, especially when based on a single code. ${ }^{2,3}$ Studies that rely on nonvalidated searches may mischaracterize health outcomes, such as the overstated hazard for thin melanoma metastasis from miscoding in the Surveillance, Epidemiology, and End Results (SEER) database. ${ }^{4}$

Our group validated the ICD-9-CM codes 692.71 and 692.76 for sunburn. We searched the Research Patient Data Repository, a medical records database of patients at Partners Healthcare, for sunburns diagnosed at the emergency departments of Brigham and Women's Hospital and Massachusetts General Hospital between January 1, 2000, and December 31, 2015, using ICD-9-CM codes $692.71,692.76$, and 692.77. We manually reviewed each medical record returned to verify the diagnosis of sunburn.

We found that 196 of 214 records returned had a sunburn diagnosis, yielding an overall positive predictive value (PPV) of $91.6 \%$. Code-specific PPVs were $89.5 \%$ (153 of 171) for 692.71 and $100 \%$ (43 of 43 ) for 692.76 . We were unable to identify any cases that used code 692.77. The PPV of ICD-9-CM codes 692.71 and 692.76 supports the main search criteria in the study by Guy et $a l,{ }^{1}$ although we cannot comment on the validity or relative contribution of code 692.77 to the results.

The use of "big data" in dermatology is nascent and has the potential to transform our understanding of disease epidemiology, outcomes, and costs. While insidious errors in big data require us to validate results in multiple data sets before accepting new results, one easy first step is to make sure our baseline assumptions are correct. We therefore recommend that future publications based on administrative and/or survey data in dermatology require methods or citations that validate the search criteria of cases and covariates. No amount of analysis or data can overcome the "garbage in, garbage out" phenomenon introduced by incorrect assumptions around potentially biased data collected by surveys or for billing purposes.

\author{
Fan Di Xia, AB \\ Cara Joyce, PhD \\ Arash Mostaghimi, MD, MPA, MPH
}

Author Affiliations: Brigham and Women's Hospital, Harvard Medical School, Boston, Massachusetts (Xia); Loyola University, Chicago, Illinois (Joyce); Department of Dermatology, Brigham and Women's Hospital, Harvard Medical School, Boston, Massachusetts (Mostaghimi).

Corresponding Author: Arash Mostaghimi, MD, MPA, MPH, Department of Dermatology, Harvard Medical School, Brigham and Women's Hospital, 75 Francis St, PBB-B 421, Boston, MA 02115 (amostaghimi@bwh.harvard.edu).

Published Online: April 12, 2017. doi:10.1001/jamadermatol.2017.0252

Conflict of Interest Disclosures: None reported.

1. Guy GP Jr, Berkowitz Z, Watson M. Estimated cost of sunburn-associated visits to US hospital emergency departments. JAMA Dermatol. 2017;153(1):90-92.

2. Davis RL, Gallagher MA, Asgari MM, et al. Identification of Stevens-Johnson syndrome and toxic epidermal necrolysis in electronic health record databases. Pharmacoepidemiol Drug Saf. 2015;24(7):684-692. 
3. Hsu D, Brieva J, Nardone B, Silverberg J. Validation of database search strategies for the epidemiological study of pemphigus and pemphigoid. $\mathrm{Br} J$ Dermatol. 2016;174(3):645-648.

4. Gimotty PA, Shore R, Lozon NL, et al. Miscoding of melanoma thickness in SEER: research and clinical implications. J Invest Dermatol. 2016;136(11):2168-2172.

In Reply We appreciate the interest in our analysis ${ }^{1}$ by Xia and colleagues and their discussion of our use of the International Classification of Diseases, Ninth Revision, Clinical Modification (ICD-9-CM) for code validation. As they have indicated, the positive predictive values of ICD-9-CM codes 692.71 (first-degree sunburn) and 692.76 (second-degree sunburn) support our search criteria. The remaining code used in our search criteria, ICD-9-CM code 692.77, is for third-degree sunburn. This event is highly unusual, so it is not a surprise that they found no cases with this code in their data set. Although we did not analyze our data by specific codes, we did note that there were only $11(0.15 \%)$ visits in our data set with a code of 692.77.

We acknowledge the potential pitfalls with the validity of hospital administrative data. Since the data used were deidentified and not linked to medical records, we were unable to validate the billing codes for this particular analysis. National data on sunburn are generally collected through self-report and are therefore also subject to validity concerns, albeit of a different sort (eg, we know that peoples' perception of sunburn varies and is subjective).

Despite these limitations, we found that nearly 34000 visits were made to an emergency department in 2013 to seek treatment for sunburn, at a cost of over $\$ 11$ million. These findings highlight the importance of reducing overexposure to UV radiation in an effort to prevent sunburns and future cases of skin cancer.

Gery P. Guy Jr, PhD, MPH

Zahava Berkowitz, MSPH, MSc

Meg Watson, MPH
Author Affiliations: Division of Cancer Prevention and Control, National Center for Chronic Disease Prevention and Health Promotion, Centers for Disease Control and Prevention, Atlanta, Georgia.

Corresponding Author: Gery P. Guy Jr, PhD, MPH, Division of Cancer Prevention and Control, Centers for Disease Control and Prevention, 4770 Buford Hwy, MS-F76, Atlanta, GA 30341 (irm2@cdc.gov).

Published Online: April 12, 2017. doi:10.1001/jamadermatol.2017.0253

Conflict of Interest Disclosures: None reported.

1. Guy GP Jr, Berkowitz Z, Watson M. Estimated cost of sunburn-associated visits to US hospital emergency departments. JAMA Dermatol. 2017;153(1):90-92.

\section{CORRECTION}

Incorrect Figure: In the Original Investigation titled "Comparison of Posttransplant Dermatologic Diseases by Race,"1 published online March 8, 2017, some of the bar heights in Figure 1 were incorrect. Figure 1 has been replaced. This article has been corrected online.

1. Chung CL, Nadhan KS, Shaver CM, et al. Comparison of posttransplant dermatologic diseases by race [published online March 8, 2017]. JAMA Dermatol. doi:10.1001/jamadermatol.2017.0045

Typographical Errors and Missing Table Footnote: In the article titled "StevensJohnson Syndrome and Toxic Epidermal Necrolysis Standard Reporting and Evaluation Guidelines: Results of a National Institutes of Health Working Group,"1 published online March 15, 2017, there were typographical errors in both the Figure and the Table, and there was a missing footnote in the Table. This article has been corrected online.

1. Maverakis E, Wang EA, Shinkai K, et al. Stevens-Johnson Syndrome and toxic epidermal necrolysis standard reporting and evaluation guidelines: results of a National Institutes of Health working group [published online March 15, 2017]. JAMA Dermatol. doi:10.1001/jamadermatol.2017.0160

Errors in Figure Panel Labels: In the case report titled "BRAF V600E mutation in involuting nevus in a patient treated with vemurafenib,"1 published online March 1,2017 , the Figure panel labels for panels C and D were incorrect. Each should read "Nevus specimen after complete excision." This article was corrected online.

1. Millán-Cayetano JF, Fernández-Canedo I, Blázquez-Sánchez $\mathrm{N}$, Fúnez-Liébana R, de Troya-Martín M. BRAF V600E mutation in involuting nevus in a patient treated with vemurafenib [published online March 1, 2017]. JAMA Dermatol. doi:10.1001/jamadermatol.2016.6091 